A new tool for monitoring (child) poverty: measures of cumulative deprivation

\author{
Corresponding author: Geranda Notten \\ University of Ottawa \\ Graduate School of Public and International Affairs \\ 55 Laurier East \\ Ottawa, K1N 6N5, Ontario, Canada \\ gnotten@uottawa.ca \\ Tel: + 16135625800 ext. 4794 \\ Fax: +1 613-562-5241 \\ Keetie Roelen \\ University of Sussex \\ Institute of Development Studies \\ Brighton, BN1 9RE, United Kingdom
}

\begin{abstract}
Governments' social indicator portfolios have expanded taking the multidimensionality of poverty into account. However, few if any, of the indicators provide insight into the degree to which persons experience several unfavourable conditions at the same time. This paper reviews and tests various indicators of cumulative deprivation that can be used to monitor child poverty and to identify vulnerable groups of children. This paper studies headcounts (counting deprived individuals) and adjusted headcounts (counting deprivations of deprived individuals) while the cumulative threshold can be distribution dependent (relative) or not (absolute). The measures are empirically tested on the 2007 EU-SILC data for the United Kingdom, Germany, France and the Netherlands. The findings indicate that the absolute adjusted headcount with a cumulative threshold of one deprivation is the most attractive candidate: it has an intuitive interpretation; it is sensitive to the breadth of deprivations but not oversensitive to changes in the methodology.

Keywords: poverty measurement, multidimensional poverty, material deprivation, cumulative deprivation, child poverty
\end{abstract}


To monitor poverty and identify vulnerable groups, poverty research has traditionally relied on measuring household's resources such as income and expenditures. Nowadays, monetary poverty indicators are increasingly complemented with other social indicators. Seminal work including Peter Townsend's study on poverty in the United Kingdom (1979) and Amartya Sen's work on capabilities (1985) contributed to a paradigm shift: as poverty is multidimensional, policymaking requires monitoring information on multiple dimensions. Consequently, indicators covering dimensions such as material well-being, housing, health, education and social inclusion have become part of governments' social indicator portfolios. For instance, under the umbrella of the Open Method of Coordination (OMC), the European Union (EU) annually publishes a set of commonly defined social exclusion indicators including the percentage of people that cannot afford meat every second day and the percentage of people living in overcrowded housing.

While such indicators illustrate the share of the population experiencing an unfavourable outcome, they can also be used to provide insight into cumulative deprivation at an individual level i.e. the degree to which a person is affected by several conditions at the same time. By combining information from single indicators into one composite indictor, indicators of cumulative deprivation are able to capture the breadth of deprivation experienced by a person. From a well-being perspective this is relevant information: if, for instance, $10 \%$ of the population lives in overcrowded housing and $10 \%$ of the population are unable to afford meat once every two days, a person experiencing both conditions ceteris paribus is worse off than someone experiencing one condition. ${ }^{1}$ On a policy level, a cumulative deprivation indicator can be used to assess the average breadth of deprivation in a population and to identify which population groups are more likely to be affected by cumulative deprivation. Addressing the circumstances of groups with a wider breadth of deprivation might be given a higher priority and the recommended policy response could also be different than that for groups experiencing only one deprivation. Finally, with expanding social indicator portfolios, a cumulative deprivation indicator can serve as a headline figure and a point of departure for analyzing single indicators.

\footnotetext{
${ }^{1}$ We use the term well-being as synonymous to welfare and referring to a person's contented state of being happy, healthy and prosperous. In some scholarly traditions an explicit distinction is made between welfare and well-being (see for instance van Praag and Paul Frijters, 1999) and the type of deprivation indicators studied here would be classified as indicators of welfare rather than well-being.
} 
Indicators of cumulative deprivation could thus be a valuable addition to governments' social indicator portfolios and, with advances in measurement theory and data collection there are now ample opportunities for estimating such indicators. Over the past years, many new measures of multidimensional poverty have been proposed and some of those are capable of capturing cumulative deprivation at an individual level (Alkire, S., \& Foster, J., 2011; Alkire \& Santos, 2009; Chakravarty, 2006; Duclos, Sahn, \& Younger, 2006; Nolan \& Whelan, 2007; Thorbecke, 2008; Tsui, 2002). Furthermore, to measure cumulative deprivation, the deprivation information should be available for every person. The introduction of new social indicators not only resulted in more and better data on multiple dimensions of poverty but it also increased the availability of individual level data. In light of these new measurement methods, the available information is still underexploited. The EU, for instance, has recently adopted its first indicator of cumulative deprivation: this so-called primary indicator of material deprivation reflects the percentage of people experiencing at least 3 out of 9 material deprivations (Guio, 2009). This indicator, however, is not sensitive to changes in the breadth of deprivations of deprived persons (i.e. when a person with three deprivations becomes deprived in one more indicator) and it ignores changes in the breadth of deprivations of persons with less than three deprivations. On the other hand, it is not yet clear whether implementing the new poverty measures on the current data will yield empirically robust and policy relevant results. For instance, unlike the information used to measure monetary poverty, most deprivation information is stored in binominal variables (i.e. whether someone is unable to afford meat once every second day). This not only implies that information on the depth of deprivation is often not available (i.e. whether one can afford meat a few times a week or only once) but it might also make the measure empirically more sensitive to seemingly small variations in the method of estimation.

In this context of new measurement methods, better data and currently used indicators, the aim of this paper is to evaluate which indicator(s) of cumulative deprivation would be promising candidates to be included in governments' social indicator portfolios. The approach taken in this paper is to implement and empirically test recently developed measures of cumulative deprivation on current data. Furthermore, in our application we focus on children rather than the population as a whole. While this research yields insights on the measurement of cumulative deprivation in general, measuring cumulative disadvantage is even more pertinent for children: children's current well-being is a key determinant of their future well-being; their well-being in 
one domain (i.e. health) could influence that in another domain (i.e. education); and children have little control over, or responsibility for, the factors determining their well-being. The candidate measures are tested in four EU member states (Germany, France, Netherlands and the United Kingdom (UK)) using the 2007 wave of the European Statistics on Income and Living Conditions (EU-SILC). The behaviour of the measures is empirically tested by means of various sensitivity analyses. Given the potential policy uses, the results are analyzed from a national and EU perspective: child poverty has dominated the UK social policy agenda for the past decade and the EU is in search for child specific indicators for its social indicator portfolio.

The next section briefly reviews the conceptual origins of multidimensional poverty as these ideas have resulted in the promotion of holding a broad social indicator portfolio. Thereafter, a theory section sets out criteria for measurement and presents the candidate measures. The subsequent section discusses the method of estimation of the measures on the EU-SILC data and presents the benchmark estimates. Then, the measures are empirically tested to assess their sensitivity to methodology changes. The final section concludes and connects the findings to policy.

\section{Multidimensional poverty}

Indicator portfolios of developed and developing country governments have expanded in response to a paradigm shift ignited by influential scholars such as Streeten et al (1981), Sen $(1985 ; 1999)$ and Townsend $(1979 ; 1987)$ who argued that well-being is multidimensional. Streeten and his co-authors argued that only the fulfillment of basic needs, material and nonmaterial, will give individuals the opportunity of a full life and that, consequently, development policy should focus on eliminating basic needs deprivation (p. 21). Sen conceptualizes poverty as "the deprivation of basic capabilities rather than merely as lowness of incomes" where capabilities are understood to be the substantive freedoms that a person has to lead the kind of life she has reason to value" (1999, p. 87). He distinguishes between political freedoms, economic facilities, social opportunities, transparency guarantees and protective security (1999, p. 38). In contrast to Streeten and Sen, who emphasize the absolute nature of basic needs or capabilities concepts, Townsend $(1979 ; 1987)$ argues that poverty can only be defined in relation to the society to which a person belongs. He defines poverty as the lack of resources and 
deprivation as the "lack [of] types of diet, clothing, housing, household facilities and fuel and environmental, educational, working and social conditions, activities and facilities which are customary" (1987, p. 125-126).

Notwithstanding their differences, these approaches all distinguish between means (including income) and ends (be they needs, capabilities or deprivation) and they emphasize the importance of monitoring them. These ideas have been at the root of sustained initiatives collecting and monitoring a wide range of indicators such as the Human Development Index, the Millennium Development Indicators, Multiple Indicator Cluster Surveys and numerous household surveys yielding indicators on living conditions in developed and developing countries, including the European Union's indicators on poverty and social exclusion.

\section{Measures of cumulative deprivation: theory}

The expanded social indicator portfolios thus take better account of the multidimensionality of poverty and well-being but there is still scope for improvement. Typically, these indicators summarize one aspect of well-being, either at a population level or for a subgroup of the population. Few, if any, measures combine the information from single indicators to capture the breadth of deprivations experienced by a person. Figure 1 illustrates this issue by summarizing the deprivation indicators covering three well-being aspects for three persons. The first person does not suffer from any deprivations while the second person is deprived in the second indicator and the third person is deprived in the second and third indicators. All other things equal, the third person is worse off than the other deprived person but this difference goes unnoticed when only single indicators are reported. Cumulative deprivation indicators are sensitive to this distinction because they combine the information from several indicators into one number. ${ }^{2}$ This section introduces such measures.

[Insert Figure 1 here]

\footnotetext{
${ }^{2}$ A cumulative deprivation indicator captures the breadth of deprivations (i.e. whether a person experiences poor housing conditions and is, at the same time, unable to afford meat every two days). Information on the depth of deprivation (i.e. whether one lives in extremely poor or poor housing conditions) is also important but such information is much less available because indicators are often binominal (informing whether someone experiences a particular condition but not how severe it is).
} 
Ideally, a cumulative deprivation measure should satisfy two criteria. Firstly, it should be sensitive to cumulative deprivation and changes therein. The measure should capture that the third person has one more deprivation than the second person and, if the third person becomes deprived in one more indicator, the measure should increase. This criterion is also known as the axiom of dimensional monotonicity (Alkire \& Foster, 2011). Secondly, monitoring progress on these and other measures is of interest to policymakers, researchers, politicians and other interest groups. The number should thus be relatively easy to interpret for a broad audience. At minimum, a larger number should indicate a higher level of cumulative deprivation but ideally it should also have a more tangible, intuitive interpretation.

This paper adopts the following terminology: when a specific aspect of a person's well-being falls below a minimum, that person is deprived. This minimum is a deprivation threshold; following Townsend, this threshold is inspired by prevailing standards in the society in which that person lives. Cumulative deprivation reflects the degree to which a person experiences multiple deprivations. The cumulative deprivation threshold expresses the minimum number of deprivations a person should have to be cumulatively deprived. The cumulative deprivation measure is an aggregate index that provides a specific insight into the extent of cumulative deprivation as experienced by individuals in a given society.

The measures fall into two subgroups: headcounts, counting deprived individuals, and so-called deprivation-adjusted headcounts, counting the deprivations of deprived individuals (Alkire, 2008). Furthermore, cumulative deprivation threshold can depend on the distribution of deprivations in a society (i.e. whether it is relative) or not (absolute).

\subsection{Cumulative Deprivation Headcount (CDH)}

Analogous to the well-known poverty headcount index (Foster, Greer, \& Thorbecke, 1984), the $\mathrm{CDH}$ measures the number of cumulatively deprived persons as a percentage of the population. With a cumulative deprivation threshold of one deprivation, the second and third person (Figure 1) are cumulatively deprived resulting in a $\mathrm{CDH}$ of $66 \%(2 / 3 * 100 \%)$. The $\mathrm{CDH}$ is very intuitive to interpret but it is not always sensitive to changes in deprivations: if the second person becomes deprived in one more indicator, the index remains unchanged while the breadth of deprivation increases. Hence, it does not satisfy the axiom of dimensional monotonicity. An example of this 
measure is the EU's primary indicator of material deprivation where the cumulative deprivation threshold is set at 3 (out of 9) material deprivations (Guio, 2009).

\subsection{Cumulative Deprivation Index (CDI)}

The CDI counts deprivations of cumulatively deprived individuals. The breadth of deprivations is expressed as the ratio of observed deprivations over the maximum possible deprivations; these ratios are summed over all cumulatively deprived individuals and subsequently divided by the total population. Keeping the cumulative deprivation threshold at one, the second person in Figure 1 has a ratio of 1 out of $3(0.33)$ and the third person has a ratio of 2 out of $3(0.66)$; the CDI is then 0.33 (0.99/3). Thus, on average, a person in this society is deprived in $33 \%$ of the indicators. When the cumulative threshold is set at a higher number, individuals with fewer deprivations than the threshold are excluded from the numerator but still counted in the denominator. This comes at a loss of intuitive interpretation; the resulting number reflects the percentage of deprivations experienced by the cumulatively poor averaged over the total population. Unlike the $\mathrm{CDH}$, the $\mathrm{CDI}$ is sensitive to changes in the breadth of deprivations.

\subsection{Cumulative deprivation threshold: distribution dependent or not?}

The cumulative deprivation threshold can depend on the distribution of deprivations in society or it can be determined on other grounds. To start with the latter, if non-deprivation in one indicator can compensate for deprivation in another indicator, the indicators are substitutes (Atkinson, 2003). If this holds for all indicators, only a person deprived in all indicators would be considered deprived; this is the so-called intersection approach. If, on the other hand, deprivation indicators are complementary (deprivation in one indicator affects well-being in another indicator) a so-called union approach is warranted; a person is deprived if she is at least deprived in one indicator. Though it offers no guidance in where exactly to establish the threshold, the dual-cut off is the middle of the road solution: a person should have several indicators deprivations. The EU's primary indicator of material deprivation uses a dual cut off where the cumulative deprivation threshold is set at 3 (out of 9) material deprivations.

Can a person deprived in two indicators be considered disadvantaged if being deprived in two indicators is rather common in that society? Is a person with two deprivations living in a country with high deprivation levels, equally worse off than a person with two deprivations living in a 
country with low deprivation levels? Even though the deprivation indicators are constructed on the basis of prevailing customs in a society, such questions arise naturally if i) one considers deprivation to be a relative phenomenon as in Townsend's definition, ii) one uses one set of indicators for different societies (such as the European Union), iii) one uses the same set of indicators over time while the average living standard increases. One way to control for 'normal' deprivation levels in a society is by following standard practise in relative income poverty: set the cumulative threshold relative to the median deprivations in the population. Comparative studies of monetary poverty commonly set the threshold at 50 or $60 \%$ of median income ${ }^{3}$. In the context of measuring deprivations, a person could thus be considered cumulatively deprived when she has 50 or $60 \%$ more deprivations than the median person. In our example the second person is the median person having one deprivation, thus the relative threshold is set at 1.5 or 1.6 deprivations implying that only the third person is cumulatively deprived. Thereafter, one can compute the relative counterparts of the $\mathrm{CDH}(33 \%)$ and CDI (22\%).

The relative measures thus compare the cumulative disadvantage of a person relative to that of her peers. Though the relative measures are sensitive to changes in the breadth of deprivations of the cumulatively deprived, it should be noted that they are also sensitive to changes in the nonpoor population: as the distribution of deprivations is used to establish the relative cumulative threshold, changes in the number of non-cumulatively deprived persons may affect the threshold and thus the relative measures.

Concluding, the CDI with a cumulative deprivation threshold of one satisfies both criteria: sensitivity to changes in breadth of deprivation and ease of interpretation. For a cumulative threshold above one, the CDI loses its intuitive interpretation. The $\mathrm{CDH}$, on the other hand, has an intuitive interpretation but it is often not sensitive to changes in the breadth of deprivation. The next section explains how to estimate these measures for children in Germany, France, the Netherlands and the UK.

4. Method of estimation

\footnotetext{
${ }^{3}$ When calculating income poverty the OECD sets the relative threshold at $50 \%$ of the median while the EU sets the relative threshold at $60 \%$ of the median.
} 
Estimating cumulative deprivation requires choosing a data source, indicators, thresholds and a method of aggregation, with each choice influencing the estimates. This section discusses these choices and indicates where tests are needed.

\subsection{Data}

Measuring cumulative deprivation of persons in an EU context requires cross-nationally comparable and individual level data. The EU-SILC data meet these requirements: data are collected for every member state providing nationally representative household and individual level information, including many social indicators (European Commission, June 2010). While the 2007 wave holds data for 26 countries we restrict the sample to Germany ${ }^{4}$, France, the Netherlands and the UK. As the EU-SILC data are constructed ex post by harmonizing information from national surveys, differences in the formulation of questions and data collection processes may also affect countries' deprivation levels. To minimize the impact of such comparability errors, we compared questionnaires and analyzed descriptive statistics for the 15 oldest member states. We further restricted the sample to countries having similar living standards but different labour markets, social protection and tax systems (e.g. Whelan \& Maître, 2010; Whelan, Nolan, \& Maître, June 2008). This sample enables us to study the impact of methodological choices on the empirical behaviour of the measures by exploiting the natural variation in child deprivation outcomes between countries while controlling for cross-national differences in the (average) living standard and data collection. As this paper focuses on child poverty, children (age 0-17 years) are the unit of analysis.

\subsection{Deprivation indicators}

The deprivation indicators have been selected following a number of conceptual guidelines that, when contrasted with the available information, also reveal the challenges of estimating a composite measure of well-being (see Notten \& Roelen, November 2010 for an extensive discussion). Table 1 lists the indicator definitions and the descriptive statistics.

\footnotetext{
${ }^{4}$ Comparison between the 2005 Microcensus, German Socio-Economic Panel (GSOEP) and EU-SILC suggest the population groups such as very young children (age 0-4), adults with low education and certain groups of immigrants are underrepresented in the EU-SILC (Hauser, 2008). As the latter two characteristics are known to be associated with an increased risk of poverty, this paper may underestimate levels of (cumulative) deprivation in Germany.
} 
Firstly, a lack of resources (be they public or private) can potentially translate into various material and non-material deprivations. Ideally, the selected indicators should reflect that diversity. The data only cover four sub-domains of material deprivation: housing conditions (3 indicators), neighbourhood conditions ( 2 indicators), access to basic services ( 2 indicators) and financial means (6 indicators). These indicators are all measured at a household level and they largely overlap with those used in other studies (Bradshaw \& Richardson, 2009; Dewilde, 2004; Whelan et al., 2001). Consequently, the cumulative deprivation estimates will reflect the conditions in which children live, rather than how these conditions impact their well-being. We would have preferred to include child specific indicators in domains such as health, education and social interaction but this information is not available in the EU-SILC. ${ }^{5}$ Data limitations thus constrain the selection of indicators resulting in an incomplete (missing domains) and uneven (26 indicators per domain) picture of multidimensional child well-being.

[Insert table 1 here]

Secondly, as deprivation indicators are inherently normative, they "should identify the essence of the problem and have a clear and accepted normative interpretation" (Atkinson, Cantillon, Marlier, \& Nolan, 2002, p. 21). According to the Eurbarometer survey, many of the selected indicators in Table 1 are perceived as social necessities by $50 \%$ or more of the respondents to the 2007 Eurobarometer survey. For one indicator (affordability of a computer) only 20-26\% of the respondents in our subgroup of countries deemed it a necessity (Dickes, Fusco, \& Marlier, 2010). We included this item because approval rates will likely increase over time, particularly for families with children. Though generally deemed important for child well-being, approval rates for some indicators are not available because they have not been included in the Eurbarometer survey (access to primary health care and compulsory school and ability to make ends meet).

Thirdly, our concept of child well-being includes a child's 'being' and 'becoming' since these notions interact with and complement each other (Uprichard, 2008, p. 303). A deprivation indicator can thus reflect a child's 'being' and/or 'becoming'. For instance, a child living in a household that is unable to afford a computer might be affected in several ways: firstly, she has (more) difficult access to a key resource used in social interactions with her peers; secondly, she

\footnotetext{
${ }^{5}$ The 2009 wave which will be released soon also includes a child module.
} 
has fewer opportunities to gain proficiency in working with computers. Both interpretations are relevant for child well-being (Notten \& Roelen, November 2010, p. 10-15).

Fourthly, the principle of universality requires that indicators should be relevant across our subgroup of EU member states (Ruggeri Laderchi, Saith, \& Stewart, 2003, p. 244). We excluded the affordability of a fridge and washing machine because deprivation rates were extremely low in our sample. Such indicators may be included in an EU wide analysis because they are (still of) relevance in the majority of those member states.

Fifthly, in an ideal world the choices of domains, indicators and thresholds are separate and consecutive methodological steps when constructing a multidimensional poverty measure (Alkire \& Santos, 2009). In practice, these choices are highly interdependent as information is often stored in ordinal variables. For instance, the survey question "[Can] the household can afford a meal with meat, chicken or fish (or equivalent vegetarian) every second day" reflects a possible outcome that could result from insufficient financial means (European Commission, March 2009). Respondents can answer with "yes", "no" or they can refuse to answer. For nine of the indicators the question was thus formulated. For four of the indicators there were several options for setting the deprivation threshold (overcrowding, access to primary health care and compulsory school and ability to make ends meet). We can therefore test the impact of the indicator threshold on the estimates in the sensitivity analysis.

While this indicator portfolio is far from perfect and points towards the need for collecting better data on child well-being, it offers a sample of 13 indicators that can be used to provide methodological and empirical insights on how best to measure cumulative deprivation.

\subsection{Descriptive statistics}

The deprivation rates in Table 1 reveal a diverse picture of child deprivation across indicators. Deprivation rates differ considerably across indicators: indicators referring to the affordability of a holiday, the experience of pollution or environmental problems and the presence of leaks or damp in the house have relatively high deprivation rates (13-32\%) while indicators referring to the affordability of assets such as a computer or car are considerably lower (2-7\%). Deprivation rates tend to be the lower in the Netherlands but country rankings are not consistent across different indicators: whilst the UK portrays the highest crime deprivation rates (28\%) and the 
lowest deprivation rate with respect to pollution (13\%), it is the opposite for Germany (12 versus $21 \%)$.

[Insert Figure 2 here]

Figure 2 displays the cumulative distribution of deprivations ranking the child population from children experiencing many deprivations to those having no deprivation. Many children are deprived in one or more indicators (57-69\%). Most children have one deprivation (ranging from $25-29 \%$ ) but quite some children also have two or three deprivations (ranging from 6-18\%). Less than five percent of children live in households suffering from 6 or more deprivations. The Dutch distribution consistently lies below that of the other countries indicating that the degree of cumulative deprivation is lowest among Dutch children. Next best off is Germany while the French and UK distributions overlap until four deprivations after which the French distribution improves relative to that of the UK.

\subsection{Cumulative deprivation threshold}

We set the relative cumulative deprivation threshold at $50 \%$ of the median as this closely corresponds to the relative threshold of the EU at-risk-of-poverty indicators which is set at $60 \%{ }^{6}$ The cumulative deprivation distribution in Figure 2 shows that the median number of deprivations is one for each of the four countries implying that children with two or more deprivations are cumulatively deprived according to the relative measures. For the absolute measures, we take a union approach because including all deprived children enhances the intuitive interpretation of the estimates (as discussed in section 3) but in the sensitivity analysis we test several dual cut-offs.

Irrespective of whether the threshold is relative or absolute, Figure 2 already shows that a change in threshold will have a large impact on cumulative deprivation levels. For instance, a change in threshold from two to three deprivations reduces the cumulatively deprived population by $14-18$ percentage points.

\subsection{Weights}

\footnotetext{
${ }^{6}$ Unless the median number of deprivations is 10 , the cumulative deprivation thresholds will be the same with a $50 \%$ or $60 \%$ threshold.
} 
Constructing a composite index on cumulative deprivation requires a judgement on the relative importance of each indicator/domain (DeCanq \& Lugo, Forthcoming). Our default option is to give equal weight to the indicators meaning that each type of deprivation is valued equally. The advantage is that the cumulative deprivation estimates will retain an intuitive interpretation (the percentage of cumulatively deprived persons; the average percentage of deprivations). Moreover, rather than assigning equal weights to the four sub-domains (as is done for a comparative multidimensional poverty study in developing countries in Alkire and Santos (July 2010, p. 17)), we assign equal weights to indicators. This is a pragmatic choice that is firstly driven by statistical evidence from several other studies using the EU social indicators suggesting that there is disagreement in how to sort those indicators into various sub-domains. ${ }^{7}$ Secondly, we already discussed that gaps in the data (i.e. lack of child specific indicators of material deprivation and missing domains such as health or education) do not allow constructing a measure that adequately covers the potential breadth of deprivation. This means that those aspects for which data are not available get a weight of zero. While it is not possible to test the impact of missing data, we test how sensitive the measures are to the exclusion of a deprivation indicator.

Moreover, deprivation indicators could alternatively be weighted following a frequency-based or a stated-preferences method (DeCanq \& Lugo, Forthcoming). Underlying the frequency-based method is the argument that it is worse to be deprived when most people are not. This argument is implemented by assigning a weight to each indicator that depends on the deprivation rate; indicators with lower deprivation rates thus get a higher weight. The stated-preferences method, on the other hand, is based on prevailing norms in society. Items or aspects of higher value to the average population should get a higher weight than those that are less valued. This method can be implemented by using opinion surveys such as the Eurobarometer to determine the weight of each indicator. While we cannot test the effect of the stated preference method because some

\footnotetext{
${ }^{7}$ While our indicators overlap considerably with those of other studies, domains definitions differ between studies (Bradshaw \& Richardson, 2009; Dewilde, 2004; Whelan, Layte, Maître, \& Nolan, 2001). For the UK and Belgium, DeWilde (2004) has similar indicators in financial strain domain but the latent variable analysis (1994-1999 panels) suggests that they should be divided over two domains labeled 'limited financial means' and 'financial stress'. Using factor analysis, Whelan, Layte, Maître and Nolan, (2001, p. 361) find five domains for all countries in the European Community Household Panel (1994-2000). Their two lifestyle domains overlap with our financial strain domain but the authors sometimes also group both domains in one. Their environment domain overlaps with our neighborhood domain while our housing indicators are spread between their housing and environment domain. In addition to indicators from other data sources, Bradshaw and Richardson (2009) group monetary poverty, economic strain and lack of consumer durables in one 'material domain' and housing and neighborhood indicators into another domain.
} 
indicators are not included in the Eurobarometer survey, we test the impact of a frequency based method.

\section{Results}

This section analyses cumulative deprivation among children living in the UK, France, Germany and the Netherlands by comparing the deprivation estimates between measures, countries and population groups.

\section{[Insert Figure 3 here]}

The Cumulative Deprivation Headcount (CDH) shows the percentage of children that are living in cumulatively deprived households (Figure 3): 57\% of Dutch children experience deprivation in an absolute sense (having at least one deprivation) while $28 \%$ experience deprivation in a relative sense (having at least two deprivations). Deprivation levels for UK, French and German children are higher varying from $65-69 \%$ for the absolute threshold to $40-42 \%$ for a relative threshold. Cumulative deprivation rates are much higher than income poverty rates ${ }^{8}$ which vary from 14-15\% for the Netherlands, Germany and France to $23 \%$ in the UK (Table 2).

The Cumulative Deprivation Index (CDI) adds another insight as it focuses on the number of deprivations. With a portfolio of 13 indicators, a score of 7.7 means that children experience on average one deprivation (1/13) while a score of 15.4 indicates an average of two deprivations (2/13). For the absolute CDI, this percentage is $8.5 \%$ for the Netherlands, $12.0 \%$ for Germany, $12.6 \%$ for France and $13.1 \%$ for the UK. Whereas the CDH emphasizes that the prevalence of deprivation is high, the CDI shows that the average breadth of deprivations is modest with 1 to 2 deprivations. As the relative CDI only counts deprivations of children having two or more deprivations its scores are below those of the absolute CDI, ranging from $6 \%$ in the Netherlands to $10-11 \%$ for the other countries

Comparing between countries and irrespective of the measure, cumulative deprivation levels are clearly lowest in the Netherlands while Germany, France and the UK cluster at a higher level. For income poverty, countries cluster differently: the Netherlands, France and Germany form

\footnotetext{
${ }^{8} \mathrm{~A}$ person is income poor if her adult equivalent income falls below $60 \%$ of the national median income.
} 
one cluster and while the UK is a clear outlier. So even though the UK generally performs worst, its relative performance is much worse for income poverty than for cumulative deprivation.

[Insert Table 2 here]

A similar phenomenon occurs when comparing sub-groups in the population. Table 2 presents poverty and deprivation levels for a few groups known to have an elevated risk of income poverty: children living in single parent households, in low work intensity households ${ }^{9}$, in a rented dwelling or having foreign-born parents. We express risk as a ratio: a ratio of 1.34 for German children living in single parent households means that these children are $34 \%$ more likely to be cumulatively deprived than the average German child. As most risk ratios are above one, the characteristics are thus associated with an elevated risk of material deprivation. However, the risk ratios for the cumulative deprivation measures are lower than those of income poverty. Children with these characteristics thus appear less disadvantaged in terms of material deprivation than in terms of income poverty.

Each cumulative deprivation measure thus adds an insight to our understanding of disadvantage among children and these insights differ from that obtained through income poverty implying that there is scope for adding one or several cumulative deprivation measures to a social indicator portfolio. However, before a conclusion can be drawn, we test how robust these measures are to changes in the method of estimation.

\section{Sensitivity tests}

The usefulness of a welfare measure for policy depends on two types of responsiveness. Firstly, an effective measure should be responsive to changes in well-being. All other things equal, if a child becomes deprived in one more indicator, the cumulative deprivation measure should deteriorate. As discussed earlier, the candidate measures exhibit different degrees of responsiveness to such changes. Secondly, the measure should not be over-responsive to changes in the construction methodology. Large swings in estimates introduce uncertainty about the scope of the problem (how much cumulative deprivation is there?), the required budget (how

\footnotetext{
${ }^{9}$ This variable is constructed by computing the ratio of worked over workable months, averaged over all work age household members and subsequently categorised in four categories (WI $=0,0<\mathrm{WI}<0.5,0.5 \leq \mathrm{WI}<1, \mathrm{WI}=1)$. Low work intensity households have a value under 0.5.
} 
much funds are needed?), identification of vulnerable groups (which groups need priority?) and the scope for international learning (which country performs better and why?). Here we test the second type of responsiveness by re-estimating the cumulative deprivation measures under a number of realistic alternative decision scenarios changing the: indicator thresholds; indicator portfolio; cumulative deprivation threshold; and indicator weighting.

\subsection{Changes in indicator thresholds}

While nine out of 13 indicators are binominal, we could have chosen a more stringent threshold for four indicators: overcrowding, access to compulsory school, access to primary health care and the ability to make ends meet. For overcrowding the benchmark threshold stipulates that the dwelling should have enough rooms so that every couple, single adult, two children under age 12, two same-sex children between age 12 and 17 have their own room. A more restrictive criterion would be to allow two teenagers of different gender to share a room. For the other three variables we could have set the threshold at the response that it is 'very difficult', instead of 'difficult', to have access to basic services and to make ends meet.

[Insert Table 3 here]

We simultaneously test the impact of the more stringent thresholds for all four indicators. It is expected that fewer children will be indicator deprived thereby also reducing cumulative deprivation (Table 3). This does not happen in the Netherlands: the relative CDH and CDI increase. To facilitate the analysis of relative change between measures with different levels, we express test results as a ratio to the benchmark estimate. ${ }^{10}$ For instance, the UK has a value of 0.92 for the absolute $\mathrm{CDH}$ which means that a more stringent threshold reduces the percentage of cumulatively deprived children by eight percent but for most measures the decrease is larger varying from 10-26\%. Contrarily, in the Netherlands the RCDH increases by $73 \%$ and the RCDI increases by $5 \%$. This counterintuitive result is driven by the mechanics of the distribution dependent cumulative threshold. By making some of the indicator thresholds more stringent, fewer Dutch children are indicator deprived which also affects the cumulative deprivation distribution: the median number of deprivations for a Dutch child changes from one to zero resulting into a decreased cumulative threshold from 1.5 (thus $\geq 2$ ) to 0.5 (thus $\geq 1$ ). Though

\footnotetext{
${ }^{10}$ The point estimates for all sensitivity tests are available in the online supplementary appendix.
} 
relative poverty rates can also decline during an economic recession (Notten \& Neubourg de, 2011), the impact on the relative CDH is extremely large: the Dutch headcount rate increases from 27 to $48 \%$ turning the Netherlands from best to worst performing country. ${ }^{11}$ While the income distribution approximates a continuous distribution in large surveys, the cumulative deprivation distribution is discrete (with 13 indicators there are at maximum 14 values) and has high population densities for zero to four deprivations. A changed in threshold thus results in the inclusion or exclusion of many children. The increased Dutch CDI does not affect country rankings. This is because the relative CDI counts deprivations rather than persons: though children with one deprivation are now included, their deprivation is added to those of multiple deprived children. Given the underlying mechanics, similar effects can be expected for other sensitivity tests.

\subsection{Changes in indicator portfolio}

It is a priori not clear in which direction a change in indicator portfolio will influence the estimates. Firstly, an indicator with a high deprivation rate contributes more to the cumulative deprivation measure than one with a low deprivation rate. Secondly, the CDI's express the number of deprivations relative to the maximum possible deprivations; excluding an indicator reduces that maximum. Thirdly, the relative cumulative deprivation threshold can change.

Table 3 reports the ratios of the highest and lowest estimate resulting from excluding one indicator from the portfolio. For most countries, the $\mathrm{CDH}$ decreases by at most $13 \%$ but for the Dutch relative $\mathrm{CDH}$ the range of estimates varies from a $3 \%$ decline to a $96 \%$ increase; in four cases, the cumulative threshold declines again from 2 to 1 deprivations. For the other countries, the CDI's either increase up to $18 \%$ or decrease up to $8 \%$. Typically, excluding high incidence indicators such as the inability to afford a one week vacation reduces the estimates while excluding a lower incidence indicator such as the inability to afford a car increases it. Due to the shifts in the Dutch cumulative threshold, country rankings for the relative CDH and CDI are not stable. For the absolute CDI measures the country rankings are rather robust rankings change only twice (experienced crime / violence / vandalism and ability to make ends meet) out of 13 possible scenarios.

\footnotetext{
${ }^{11}$ Germany and France also switch ranks for the RCDH but this is because their cumulative deprivation levels are very close and a small change could easily lead to a rank reversal.
} 


\subsection{Changes in cumulative deprivation threshold}

We could have set a higher absolute cumulative threshold and for the relative threshold we could have chosen a higher or lower percentage of the median. As the median deprivation in the four countries is one, effective increases in the relative threshold require percentages ranges of 0-49\% (1 deprivation), 150-249\% (3 deprivations) and 250-349\% of the median (4 deprivations). Given that very few children experience five or more deprivations (see Figure 2) we test the impact of a cumulative threshold up to four deprivations.

The default threshold for the absolute measures was the lowest possible, thus it is expected that the $\mathrm{CDH}$ and $\mathrm{CDI}$ decline (fewer children are included in the numerator while the child population in the denominator is unchanged). The spread in estimates between the highest and lowest threshold is very high for all measures (ranging from 0.12 to 2.08). In spite of this high sensitivity, for the absolute CDI a simultaneous change in threshold does not influence country rankings; the $\mathrm{CDH}$ of Germany and France switch ranks for a cumulative threshold of two. The relative measures follow a similar pattern.

\subsection{Changes in indicator weighting}

Instead of equal indicator weights we also test the impact of frequency weights which depend on the prevalence of deprivation in a society; indicator weights are lower if deprivation rates are higher. In the equal weights method each indicator has a weight of 0.77 (1/13); with frequency weights they vary from 0.059 for the holiday indicator to 0.085 for the car indicator. The frequency weights have little impact: the $\mathrm{CDH}$ does not change while the CDI decreases by 5$6 \%$. Guio (2009, p. 21) confirms this result for countries with relatively low deprivation rates but she finds that differences are larger for countries with higher deprivation levels. In an EU context, this means that differences between rich and poor member states are thus reduced. ${ }^{12}$

\subsection{Discussion}

These tests have deepened our understanding of how sensitive the measures are to decisions in their method of estimation but, given the context in which they are used, what level of sensitivity

\footnotetext{
${ }^{12}$ Guio (2009, p. 21) also tests the impact of stated-preferences weights (if more people find the item a necessity, the weight increases): stated-preferences weights typically yield estimates between those of equal weights and frequency weights.
} 
is acceptable? A useful reference point is the variability of the commonly used income poverty rates: the at-risk-of-poverty rates of the 15 old EU member states can vary up to $150 \%$ when the poverty threshold is changed from $60 \%$ to 40,50 and $70 \%$ of the median (Dennis \& Guio, 2003, p. 2). Due to differences in the density of the income distribution around the various thresholds, a threshold change may also affect country rankings. However, for a consecutive change in threshold, the variation between the 15 member states is much smaller (up to 50\%) and is thus less likely to induce extreme rank reversals.

Our estimates are also very sensitive to changes in the cumulative deprivation threshold (varying over a range of often more than 100\%) but they are less sensitive to changes in other parts of the methodology (varying over a range of 4 to $25 \%$ ). Except for changes in the cumulative threshold, the absolute measures are rather stable, leading occasionally to minor changes in rankings. The relative measures are very sensitive (varying up to 100\%) and regularly result in extreme rank reversals due to high between-country variation (despite similar living standards estimates vary up to $100 \%$ for the Netherlands while they vary no more than $18 \%$ for the other countries). With $27 \mathrm{EU}$ member states, whose differences between living standards are much larger, extreme rank reversals in cumulative deprivation are likely to occur frequently. At a national policy making level it is also problematic as the indices of a fast growing member state will regularly show large jumps in deprivation levels over time while actual changes in deprivation are much smoother. Using a relative threshold thus seems problematic.

\section{Conclusion}

Governments' social indicator portfolios have expanded in recent years but few, if any, of those indicators are able to capture the degree to which children are simultaneously affected by a range of unfavourable conditions. This paper reviewed and tested candidate measures to monitor cumulative deprivation among children. Distinguishing between the breadth of deprivation also helps in identifying which groups are particularly vulnerable. As the measures combine information from multiple social indicators into one number and they can also be a starting point for further analysis into the separate indicators.

The investigated measures fall into two categories: headcounts (CDH) which count deprived children and adjusted headcounts (CDI) which count the number of deprivations of deprived 
children. A further distinguishing characteristic is whether the cumulative deprivation threshold is distribution dependent (relative) or not (absolute). The ideal measure is sensitive to changes in cumulative deprivation; is relatively easy to interpret by a broad audience and is not oversensitive to small changes in the methodology. The theoretical section investigated the first two criteria. While the CDH is very intuitive, it is not always sensitive to changes in the breadth of deprivations; the CDI is intuitive and sensitive to changes in the breadth of deprivations. In both cases, having a cumulative deprivation threshold that is higher than one deprivation comes at a loss of intuition as some children with deprivations are excluded from the count (in the numerator) while they are still part of the reference population (in the denominator).

Though available data constrain the analysis (current data only cover certain aspects of child deprivation and the data only hold very limited information on the depth of deprivation), our portfolio of 13 indicators provided methodological and empirical insights on how to measure cumulative deprivation. The benchmark estimates have shown that each cumulative deprivation measure adds an insight to understanding disadvantage among children and that these insights differ from that obtained through income poverty. The sensitivity tests found that the measures are very sensitive to changes in the cumulative threshold (variation of 100\%) but that they are less sensitive to changes in other parts of the methodology (variation of 4 to $25 \%$ ). While the absolute measures are rather stable (only minor changes in country rankings), the relative measures can register increased deprivation even though fewer children are cumulatively deprived. Particularly the relative headcount can be extremely sensitive to small methodological changes (varying up to $100 \%$ ) and can lead to extreme rank reversals due to the high betweencountry variation (despite similar living standards between country variation differs from 100\% for the Netherlands to below $18 \%$ for the other countries). This is caused by the distributiondependent cumulative threshold whose shifts result in large jumps of the estimates. This feature is problematic for international comparisons and comparisons over time, both of which are relevant in an enlarged EU context.

Concluding, this research shows that including measures of cumulative deprivation into governments' indicator portfolios provides new and relevant insights into (child) poverty. It shows that an adjusted headcount (CDI) with a cumulative threshold of one is the most attractive candidate. This measure could be supplemented though with an 'extreme' headcount (CDH) 
having a higher cumulative threshold to assess the size and conditions of children that experiencing a high number of unfavourable conditions. Setting a relative threshold at a fraction of the median is not recommended. Instead, frequency weights can be used in international comparisons and comparisons over time to control for differences in living standards though this means that the estimates will lose their intuitive interpretation.

\section{Acknowledgements}

This project was undertaken under affiliation with Maastricht Graduate School of Governance, Maastricht University as part of an EU-SILC research project. Part of this research was funded by UNICEF Innocenti Research Centre (IRC) in Florence. An earlier version of this research has been published online as an Innocenti Discussion Paper titled 'Monitoring child well-being in the European Union: measuring cumulative deprivation' (Innocenti Research Centre: http://www.unicef-irc.org/publications/635). We thank Marie-Hélène L'Heureux, Jessica Breaugh, Julie Charest, Genie Wu and Kirsten Davis for their contributions to this research project. We also thank Leonardo Menchini, the participants to the Innocenti Research Seminar and two anonymous referees for their feedback.

\section{References}

Alkire, S. (2008). Choosing dimensions: The capability approach and multidimensional poverty. In N. Kakwani, \& J. Silber (Eds.), The many dimensions of poverty (pp. 89-119). Basingstoke: Palgrave-MacMillan. Retrieved from http://mpra.ub.uni-muenchen.de/8862

Alkire, S., \& Foster, J. (2011). Counting and multidimensional poverty measurement. Journal of Public Economics, 95, 476.

Alkire, S., \& Santos, M. E. (2009). Poverty and inequality measurement. In S. Deneulin, \& L. Shahani (Eds.), An introduction to the human development and capability approach, freedom and agency (pp. 121-161). London: Earthscan.

Alkire, S., \& Santos, M. E. (July 2010). Acute multidimensional poverty: A new index for developing countries (OPHI Working Paper No. 38) Retrieved from http://www.ophi.org.uk

Atkinson, A. B. (2003). Multidimensional deprivation: Contrasting social welfare and counting approaches. Journal of Economic Inequality, 1, 51-65.

Atkinson, A. B., Cantillon, B., Marlier, E., \& Nolan, B. (2002). Social indicators: The EU and social inclusion. Oxford; New York: Oxford University Press. 
Bradshaw, J., \& Richardson, D. (2009). An index of child well-being in Europe. Child Indicators Research, 2(3), 1-33.

Chakravarty, S. R. (2006). An axiomatic approach to multidimensional poverty measurement via fuzzy sets. In A. Lemmi, \& G. Betti (Eds.), Fuzzy set approach to multidimensional poverty measurement, United States: Springer, 47-72.

DeCanq, K., \& Lugo, M. A. (Forthcoming). Weights in multidimensional indices of well-being: An overview. Econometric Reviews, Retrieved from http://www.econ.kuleuven.be

Dennis, I., \& Guio, A. (2003). Poverty and social exclusion in the EU after Laeken-part 1 (Statistics in Focus: Population and Social Conditions No. Theme 3 - 8/2003). Luxembourg: Eurostat. Retrieved from http://epp.eurostat.ec.europa.eu/cache/ITY_OFFPUB/KS-NK-03008/EN/KS-NK-03-008-EN.PDF

Dewilde, C. (2004). The multidimensional measurement of poverty in Belgium and Britain: A categorical approach. Social Indicators Research, 68, 331-369.

Dickes, P., Fusco, A., \& Marlier, E. (2010). Structure of national perceptions of social needs across EU countries. Social Indicators Research, 95, 143-167.

Duclos, J., Sahn, D. E., \& Younger, S. D. (2006). Robust multidimensional poverty comparisons. The Economic Journal, 116, 943-968.

European Commission. (June 2010). 2007 comparative EU final quality report (ESTAT/F3/GRG D(2010) No. v2). Luxembourg: Eurostat. Retrieved from http://epp.eurostat.ec.europa.eu/portal/page/portal/eurostat/home

European Commission. (March 2009). Description of EU-SILC user database variables: Crosssection and longitudinal No. Version 2007.1 from 01-03-09). Luxembourg: Eurostat. Retrieved from http://epp.eurostat.ec.europa.eu/portal/page/portal/eurostat/home

Foster, J., Greer, J., \& Thorbecke, E. (1984). A class of decomposable poverty measures. Econometrica, 52(3), pp. 761-766.

Guio, A. (2009). What can be learned from deprivation indicators in Europe (Methodologies and working papers. Luxembourg: European Commission. Retrieved from http://epp.eurostat.ec.europa.eu.proxy.bib.uottawa.ca/cache/ITY_OFFPUB/KS-RA-09007/EN/KS-RA-09-007-EN.PDF

Hauser, R. (2008). Problems of the German contribution to EU-SILC: A research perspective, comparing EU-SILC, microcensus and SOEP (SOEP Papers on Multidisciplinary Panel Data Research No. 86). Berlin: The German Institute for Economic Research. Retrieved from www.diw.de

Matern, R., Mendelson, M., \& Oliphant, M. (December 2009). Developing a deprivation index: The research process. Daily Bread Food Bank and the Caledon Institute of Social Policy. Retrieved from http://www.dailybread.ca/learningcentre/documents/DevelopingaDeprivationIndexFINAL.pdf 
Nolan, B., \& Whelan, C. T. (2007). On the multidimensionality of poverty and social exclusion. In S. Jenkins, \& J. Micklewright (Eds.), Inequality and poverty re-examined, Oxford: Oxford University Press, 146-165.

Notten, G., \& Neubourg de, C. (2011). Monitoring absolute and relative poverty; 'not enough' is not the same as 'much less'. Review of Income and Wealth, 57(2), 247.

Notten, G., \& Roelen, K. (November 2010). Cross-national comparison of monetary and multidimensional child poverty in the European Union: Puzzling with the few pieces that the EU-SILC provides (BWPI Working Paper No. 135). Manchester: Brooks World Poverty Institute. Retrieved from http://www.bwpi.manchester.ac.uk

Ruggeri Laderchi, C., Saith, R., \& Stewart, F. (2003). Does it matter that we do not agree on the definition of poverty? A comparison of four approaches. Oxford Development Studies, 31(3), 243-274.

Sen, A. K. (1985). Commodities and capabilities. Amsterdam: North-Holland.

Sen, A. K. (1999). Development as freedom Oxford University Press.

Streeten, P. (1981). First things first: Meeting basic human needs in developing countries. New York: Oxford University Press.

TARKI Social Research Institute. (2010). Child poverty and child well-being in the European Union (Report prepared for the DG Employment, Social Affairs and Equal Opportunities (Unit E.2) of the European Commission). Budapest: European Commission. Retrieved from http://www.tarki.hu/en/research/childpoverty/index.html

Thorbecke, E. (2008). Multidimensional poverty: Conceptual and measurement issues. In N. Kakwani, \& J. Silber (Eds.), The many dimensions of poverty. New York: Palgrave Macmillan.

Townsend, P. (1979). Poverty in the United Kingdom: A survey of household resources and standards of living. Harmondsworth: Penguin.

Townsend, P. (1987). Deprivation. Journal of Social Policy, 16(2), 125.

Tsui, K. (2002). Multidimensional poverty indices. Social Choice and Welfare, 19, 69-93.

Uprichard, E. (2008). Children as 'Being and becomings': Children, childhood and temporality. Children and Society, 22, 303-313.

Van Praag, B. and P. Frijters (1999). The measurement of welfare and well-being: The Leyden approach, School of Economics and Finance Discussion Papers and Working Papers Series, number 071a, Queensland University of Technology, Retrieved from http://externalapps.qut.edu.au/business/documents/discussionPapers/1999/kahneman.pdf.

Whelan, C. T., Layte, R., Maître, B., \& Nolan, B. (2001). Income, deprivation and economic strain: An analysis of the European Community Household Panel. European Sociological Review, 17(4), 357-372. 
Whelan, C. T., \& Maître, B. (2010). Poverty in Ireland in comparative European perspective. Social Indicators Research, 95, 91-110.

Whelan, C. T., Nolan, B., \& Maître, B. (June 2008). Measuring material deprivation in the enlarged EU (ESRI Working Paper 249. Dublin: Economic and Social Research Institute. Retrieved from http://www.esri.ie/UserFiles/publications/20090129121820/WP249.pdf 


\section{Figures}

Figure 1: Constructing a cumulative deprivation measure: the technical problem

\begin{tabular}{|c|c|c|c|c|}
\hline & & Deprivation & & \\
\hline \multirow{4}{*}{$\begin{array}{l}\frac{n}{\pi} \\
\frac{\pi}{2} \\
\frac{0}{2} \\
\frac{2}{0} \\
\underline{5}\end{array}$} & & Indicator 1 & Indicator 2 & Indicator 3 \\
\hline & Person 1 & 0 & 0 & 0 \\
\hline & Person 2 & 0 & 1 & 0 \\
\hline & Person 3 & 0 & 1 & 1 \\
\hline
\end{tabular}


Figure 2: Cumulative deprivation distribution (by country, percentage of population by number of deprivations)

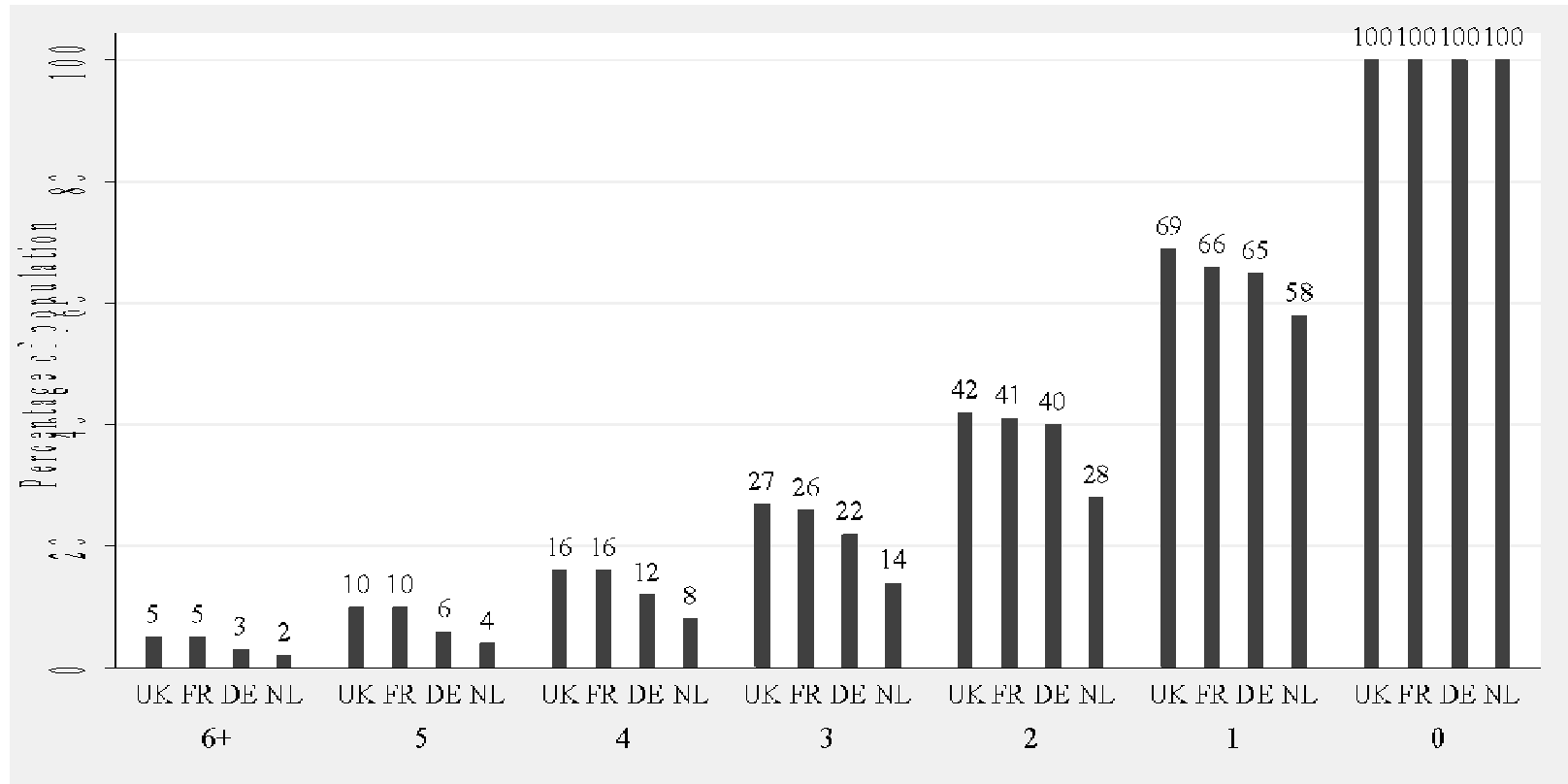

Source: EU-SILC, wave 2007. 
Figure 3: Cumulative deprivation: benchmark estimates (in percentages)

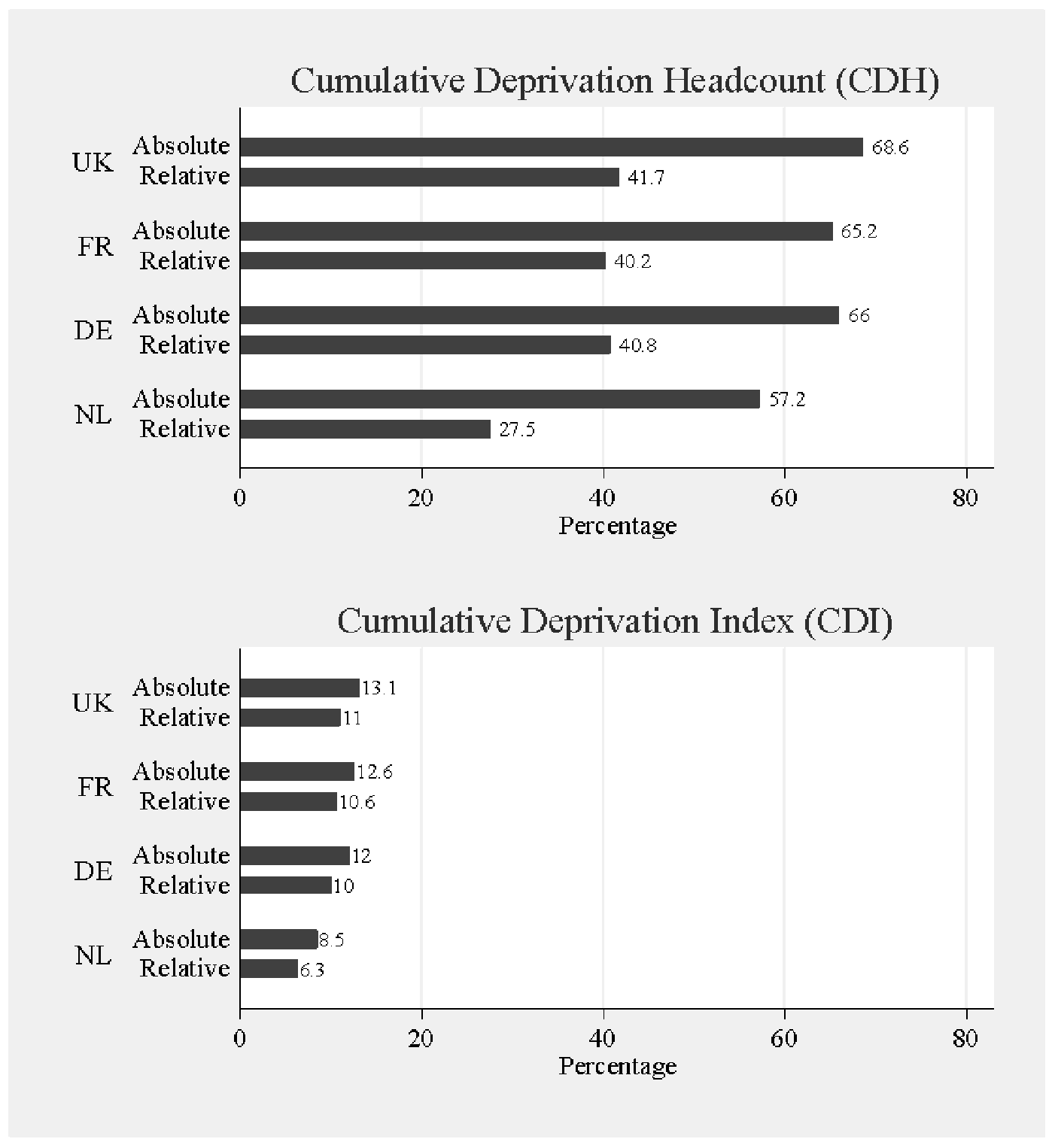

Source: EU-SILC, wave 2007. 


\section{Tables}

Table 1: Deprivation indicators (domain, definition and percentage of children) and sample size

\begin{tabular}{|c|c|c|c|c|c|}
\hline Domain & Indicator & $\mathrm{DE}$ & FR & NL & UK \\
\hline \multirow[t]{3}{*}{ Housing } & $\begin{array}{l}\text { Dwelling has leaking roof, damp walls/floors/foundation, or rot in window } \\
\text { frames or floor }\end{array}$ & 16.1 & 15.7 & 20.1 & 17.3 \\
\hline & Dwelling is not comfortably warm during winter time & 6.4 & 4.6 & 1.9 & 5.2 \\
\hline & $\begin{array}{l}\text { Dwelling is overcrowded (threshold: based upon the number of rooms and the } \\
\text { age, number of and relationships between household members, (following } \\
\text { TARKI Social Research Institute, 2010) }\end{array}$ & 9.1 & 14.9 & 4.7 & 12.0 \\
\hline \multirow[t]{2}{*}{ Neighbourhood } & Pollution, grime or other environmental problems & 20.9 & 15.4 & 13.4 & 13.1 \\
\hline & Crime violence or vandalism in the area & 12.3 & 15.5 & 17.7 & 28.3 \\
\hline \multirow[t]{2}{*}{ Basic services } & Access to primary health care services (threshold: some/great difficulty) & 12.5 & 7.6 & 8.8 & 4.7 \\
\hline & Access to compulsory school (threshold: some/great difficulty) & 16.4 & 6.8 & 7.2 & 8.1 \\
\hline \multirow[t]{6}{*}{ Financial resources } & Payment arrears on mortgage/ rent, utility bills, instalments/loan payments & 7.7 & 12.9 & 5.1 & 14.0 \\
\hline & Cannot afford meal with meat, fish or vegetarian equivalent every $2^{\text {nd }}$ day & 11.2 & 6.4 & 1.1 & 4.8 \\
\hline & Cannot afford one week annual holiday away from home & 30.1 & 32.5 & 13.7 & 30.4 \\
\hline & Cannot afford a computer for financial reasons & 2.2 & 7.0 & 0.6 & 5.5 \\
\hline & Cannot afford a car for financial reasons & 4.1 & 3.5 & 4.6 & 6.7 \\
\hline & Ability to make ends meet (threshold: with difficulty or great difficulty) & 6.7 & 20.3 & 12.1 & 20.2 \\
\hline Sample size & Children & 6,185 & 6,314 & 6,948 & 4,927 \\
\hline
\end{tabular}

Source: EU-SILC, wave 2007, module on housing conditions (dwelling is not comfortably warm during winter time, accessibility of primary health care services and compulsory school) and household data file (all other indicators). 
Table 2: Poverty profile: by selected high risk characteristics (poverty risk is expressed by ratio subgroup over child population)

\begin{tabular}{|c|c|c|c|c|c|c|}
\hline & & $\mathrm{CD}$ & & $\mathrm{CI}$ & & Income poverty \\
\hline & & Absolute & Relative & Absolute & Relative & Relative \\
\hline UK & Child population (\%) & 68.6 & 41.7 & 13.1 & 11.0 & 23.0 \\
\hline & Single parent & 1.26 & 1.65 & 1.68 & 1.88 & 1.98 \\
\hline & Low work intensity & 1.34 & 1.81 & 1.92 & 2.17 & 2.84 \\
\hline & Parents born abroad & 1.14 & 1.33 & 1.29 & 1.37 & 1.39 \\
\hline & Rented dwelling & 1.33 & 1.81 & 1.83 & 2.07 & 1.97 \\
\hline FR & Child population (\%) & 65.2 & 40.2 & 12.6 & 10.6 & 15.7 \\
\hline & Single parent & 1.27 & 1.59 & 1.67 & 1.86 & 1.87 \\
\hline & Low work intensity & 1.44 & 2.07 & 2.25 & 2.60 & 3.94 \\
\hline & Parents born abroad & 1.18 & 1.38 & 1.48 & 1.59 & 1.82 \\
\hline & Rented dwelling & 1.29 & 1.61 & 1.62 & 1.78 & 1.82 \\
\hline $\mathrm{DE}$ & Child population (\%) & 66.0 & 40.8 & 12.0 & 10.0 & 13.9 \\
\hline & Single parent & 1.34 & 1.67 & 1.82 & 2.03 & 2.82 \\
\hline & Low work intensity & 1.37 & 1.83 & 2.08 & 2.38 & 3.80 \\
\hline & Parents born abroad & 1.11 & 1.12 & 1.14 & 1.16 & 1.68 \\
\hline & Rented dwelling & 1.23 & 1.40 & 1.45 & 1.56 & 1.73 \\
\hline NL & Child population $(\%)$ & 57.2 & 27.5 & 8.5 & 6.3 & 13.9 \\
\hline & Single parent & 1.51 & 2.50 & 2.38 & 3.00 & 2.60 \\
\hline & Low work intensity & 1.46 & 2.32 & 2.34 & 2.92 & 3.12 \\
\hline & Parents born abroad & 1.18 & 1.56 & 1.46 & 1.67 & 1.80 \\
\hline & Rented dwelling & 1.42 & 2.16 & 2.05 & 2.49 & 2.45 \\
\hline
\end{tabular}


Table 3: Sensitivity tests (range of estimates, expressed as ratio test estimate over benchmark estimate)

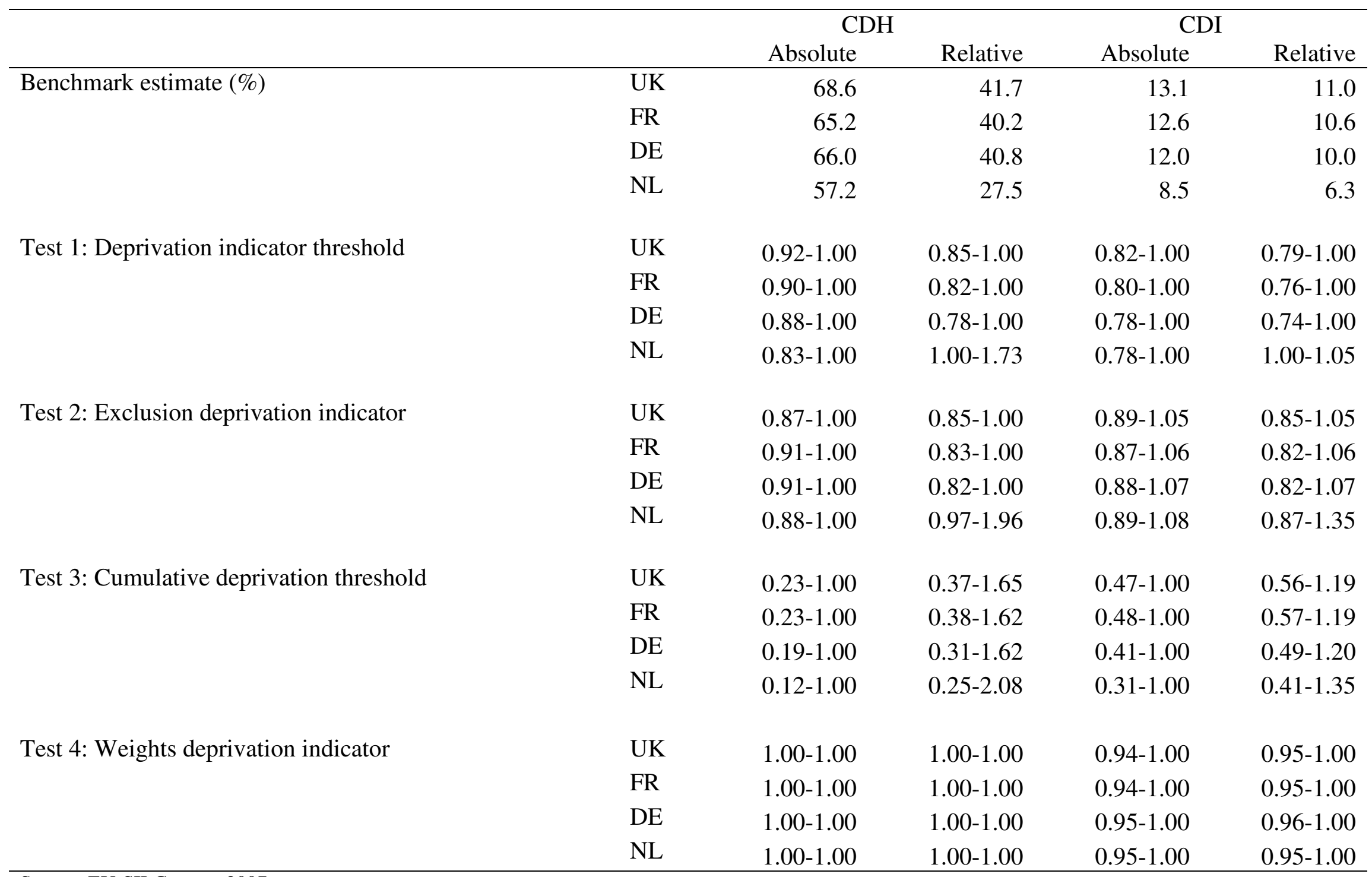

Source: EU-SILC, wave 2007. 
Supplementary appendix (online addition to article)

Table A1: Benchmark estimates

\begin{tabular}{crrrr}
\hline & $\begin{array}{c}\text { CDH } \\
\text { Absolute }\end{array}$ & $\begin{array}{c}\text { CDI } \\
\text { Relative }\end{array}$ & $\begin{array}{c}\text { CDH } \\
\text { Absolute }\end{array}$ & $\begin{array}{c}\text { CDI } \\
\text { Relative }\end{array}$ \\
\hline UK & 68.6 & 41.7 & 13.1 & 11.0 \\
FR & 65.2 & 40.2 & 12.6 & 10.6 \\
DE & 66.0 & 40.8 & 12.0 & 10.0 \\
NL & 57.2 & 27.5 & 8.5 & 6.3 \\
\hline
\end{tabular}

Source: EU-SILC, wave 2007.

Table A2: Point estimates test 1: deprivation indicator threshold

\begin{tabular}{lrrrr}
\hline & \multicolumn{2}{c}{ CDH } & \multicolumn{2}{c}{ CDI } \\
& Absolute & Relative & Absolute & Relative \\
\hline UK & 63.3 & 35.5 & 10.8 & 8.7 \\
FR & 58.7 & 32.9 & 10.1 & 8.1 \\
DE & 58.1 & 31.7 & 9.4 & 7.4 \\
NL & 47.7 & 47.7 & 6.6 & 6.6 \\
\hline
\end{tabular}

Source: EU-SILC, wave 2007.

Table A3: Point estimates test 2: Exclusion deprivation indicator

\begin{tabular}{llrrrr}
\hline & & CDH & CDI & CDH & CDI \\
& & Absolute & Relative & Absolute & Relative \\
\hline Leak & UK & 65.4 & 38.6 & 12.8 & 10.5 \\
& FR & 62.3 & 37.1 & 12.3 & 10.2 \\
& DE & 63.2 & 37.3 & 11.6 & 9.5 \\
\multirow{5}{*}{ Warm } & NL & 50.3 & 50.3 & 7.6 & 7.6 \\
& UK & 68.2 & 41.4 & 13.8 & 11.5 \\
& FR & 65.0 & 39.9 & 13.2 & 11.1 \\
& DE & 65.8 & 40.1 & 12.4 & 10.3 \\
Overcrowding & NL & 57.2 & 27.4 & 9.1 & 6.6 \\
& UK & 66.6 & 39.4 & 13.2 & 10.9 \\
& FR & 62.7 & 37.0 & 12.4 & 10.2 \\
& DE & 64.2 & 39.0 & 12.2 & 10.1 \\
& NL & 54.8 & 26.7 & 8.9 & 6.5 \\
\hline
\end{tabular}

Source: EU-SILC, wave 2007. 
Table A3 continued: Point estimates test 2: Exclusion deprivation indicator

\begin{tabular}{llrrrr}
\hline \multirow{7}{*}{ Pollution } & & $\begin{array}{c}\text { CDH } \\
\text { Absolute }\end{array}$ & $\begin{array}{c}\text { CDI } \\
\text { Relative }\end{array}$ & $\begin{array}{c}\text { CDH } \\
\text { Absolute }\end{array}$ & $\begin{array}{c}\text { CDI } \\
\text { Relative }\end{array}$ \\
& UK & 65.7 & 38.2 & 13.1 & 10.8 \\
& FR & 61.9 & 36.5 & 12.3 & 10.2 \\
& DE & 61.0 & 34.8 & 11.2 & 9.0 \\
& NL & 53.3 & 53.3 & 8.1 & 8.1 \\
& UK & 59.9 & 35.3 & 11.8 & 9.8 \\
& FR & 61.3 & 37.4 & 12.3 & 10.3 \\
& DE & 64.6 & 37.2 & 11.9 & 9.7 \\
& NL & 50.6 & 50.6 & 7.8 & 7.8 \\
Health & UK & 68.1 & 40.7 & 13.8 & 11.5 \\
& FR & 63.2 & 38.0 & 13.0 & 10.9 \\
& DE & 63.9 & 37.1 & 11.9 & 9.7 \\
& NL & 53.9 & 53.9 & 8.5 & 8.5 \\
& UK & 67.2 & 39.9 & 13.5 & 11.2 \\
& FR & 62.7 & 39.0 & 13.0 & 11.1 \\
& DE & 62.5 & 36.1 & 11.6 & 9.4 \\
& NL & 55.0 & 25.5 & 8.7 & 6.2 \\
Arrears & UK & 67.7 & 40.1 & 13.0 & 10.7 \\
& FR & 64.5 & 38.5 & 12.5 & 10.4 \\
& DE & 65.3 & 39.8 & 12.3 & 10.2 \\
& NL & 56.5 & 26.5 & 8.8 & 6.3 \\
\hline Source: EU-SLC, wave & 2007.5 & & &
\end{tabular}

Source: EU-SILC, wave 2007. 
Table A4: Point estimates test 3: Cumulative deprivation threshold

\begin{tabular}{llrrrr}
\hline & & \multicolumn{2}{c}{ CDH } & \multicolumn{2}{c}{ CDI } \\
& & Absolute & Relative & Absolute & Relative \\
\hline 1 deprivation (0-49\% of median) & UK & 68.6 & 68.6 & 13.1 & 13.1 \\
& FR & 65.2 & 65.2 & 12.6 & 12.6 \\
& DE & 66.0 & 66.0 & 12.0 & 12.0 \\
& NL & 57.2 & 57.2 & 8.5 & 8.5 \\
2 deprivations (50-149\% of median) & UK & 41.7 & 41.7 & 11.0 & 11.0 \\
& FR & 40.2 & 40.2 & 10.6 & 10.6 \\
& DE & 40.8 & 40.8 & 10.0 & 10.0 \\
& NL & 27.5 & 27.5 & 6.3 & 6.3 \\
3 deprivations (150-249\% of median) & UK & 26.7 & 26.7 & 8.7 & 8.7 \\
& FR & 25.3 & 25.3 & 8.3 & 8.3 \\
& DE & 22.9 & 22.9 & 7.3 & 7.3 \\
& NL & 13.4 & 13.4 & 4.1 & 4.1 \\
4 deprivations (250-349\% of median) & UK & 15.6 & 15.6 & 6.2 & 6.2 \\
& FR & 15.1 & 15.1 & 6.0 & 6.0 \\
& DE & 12.7 & 12.7 & 4.9 & 4.9 \\
& NL & 7.0 & 7.0 & 2.6 & 2.6 \\
\hline
\end{tabular}

Source: EU-SILC, wave 2007.

Table A5: Point estimates test 4: Weights deprivation indicator

\begin{tabular}{crrrr}
\hline & \multicolumn{2}{c}{ CDH } & \multicolumn{2}{c}{ CDI } \\
& Absolute & Relative & Absolute & Relative \\
\hline UK & 68.6 & 41.7 & 12.3 & 10.4 \\
FR & 65.2 & 40.2 & 11.9 & 10.1 \\
DE & 66.0 & 40.8 & 11.4 & 9.6 \\
NL & 57.2 & 27.5 & 8.1 & 6.0 \\
\hline
\end{tabular}

Source: EU-SILC, wave 2007. 